\title{
Early recruitment and growth of the American oyster Crassostrea virginica (Bivalvia: Ostreidae) with respect to tidal zonation and season
}

\author{
G. Curtis Roegner*, Roger Mann \\ Virginia Institute of Marine Science, School of Marine Science, College of William and Mary, Gloucester Point, \\ Virginia 23062, USA
}

\begin{abstract}
Survival and growth of newly settled oysters were measured at sub- and intertidal treatment levels during the first month of post-settlement life in the York River, Virginia, USA. Controlled settlement of hatchery-reared larvae in the laboratory and image analysis techniques allowed for individual oysters grown in the field to be tracked through time. High mortality occurred within 1 wk postsettlement at all tidal heights in 3 experiments which spanned the natural recruitment period. This initial mortality strongly influenced later abundance, as weekly mortality rates decreased sharply after 2 wk. Additionally, all recruits were eliminated from the mid-intertidal zone and above $(>25 \%$ aerial exposure) during high temperature periods. Only in autumn did recruitment occur in the intertidal area occupied by natural oyster populations. In contrast, low intertidal and subtidal populations persisted through the month long experiments where adult oysters were rare. Growth (shell area) of intertidal oysters exposed $>25 \%$ was reduced relative to more immersed oysters. Density-dependent growth was not observed. While the natural oyster population appeared to be relegated to the suboptimum intertidal, successful recruitment to this zone was limited on a seasonal basis by lethal air temperatures $>30^{\circ} \mathrm{C}$. The mortality agents which structure the intertidal population affect recently settled and juvenile oysters.
\end{abstract}

KEY WORDS: Oyster · Recruitment $\cdot$ Growth $\cdot$ Juvenile $\cdot$ Intertidal zonation

\section{INTRODUCTION}

Both pre- and post-settlement processes contribute to the demography of sessile marine organisms on hard substrates (Gaines \& Roughgarden 1985, Underwood \& Fairweather 1989, Michener \& Kenny 1991, Roughgarden et al. 1991). However, for most organisms, the problem of accurately distinguishing settlement patterns from the effects of early post-settlement mortality remains (Connell 1985). The early recruitment period, which includes settlement plus postsettlement survival, is often considered deterministic for overall recruitment success. Thus, it is important to ascertain the time course of events which structure

\footnotetext{
-Present address: Department of Oceanography, Dalhousie University, Halifax, Nova Scotia, Canada B3H 4J1
}

population distributions during the early recruitment period.

Populations of the American oyster Crassostrea virginica (Gmelin, 1791) located in higher salinity areas of the Middle and South Atlantic and Gulf coasts of the USA are commonly restricted to the intertidal zone. This zonal distribution has often been attributed to the effects of predation and competition (Galtsoff \& Luce 1930, McDougall 1942, Mackin 1946, Chestnut \& Fahy 1952, Nichy \& Menzel 1967, Ortega 1981). However, most of these investigations monitored recruitment patterns with a coarse temporal resolution (often months) and usually without quantifying variations in the relevant physical parameters such as aerial exposure, temperature, or salinity. These studies have contributed important information on recruitment trends but fail to identify when structuring phenomena occur. Similarly, few investigations have compared growth 
rates with respect to tidal inundation during the early recruitment period (but see Crosby et al. 1991).

To examine the relative contribution of larval settlement versus early post-settlement mortality on the zonal distribution of oysters, we conducted field experiments using hatchery-reared larvae in which recruitment was separated into pre- and post-settlement components. Previously, we reported the results of larval microcosm studies which demonstrated that oyster settlement occurred predominantly in the subtidal zone (Roegner \& Mann 1990). Our approach in the present investigation was to experimentally standardise the influence of larval supply by measuring mortality and growth from a known number of recently settled individuals over weekly sample periods using photographic and image analysis techniques. The objective was to ascertain the time course of mortality and growth of newly settled Crasssotrea virginica as a function of tidal exposure and season.

\section{MATERIALS AND METHODS}

Study site. Experiments were conducted in the York River, Virginia, USA, a partially mixed subestuary of Chesapeake Bay, on the Virginia Institute of Marine Science (VIMS) Ferry Pier approximately $15 \mathrm{~m}$ from shore. Water depth was $0.75 \mathrm{~m}$ at mean low water (MLW), while the tidal range at the site was approximately $1 \mathrm{~m}$. Wild Crassostrea virginica populations were distributed on pier pilings within a distinct band located between about +25 and $+50 \mathrm{~cm}$ relative to MLW. This mid-intertidal zone graded above into a distribution of the barnacle Chthamalus fragilis Darwin and below into a zone of the barnacle Balanus eburneus Gould. Green algae Ulva lactuca Linnaeus and Enteromorpha spp. were seasonally abundant throughout the intertidal zone. Substantial amounts of free space existed intertidally on the pilings below $+25 \mathrm{~cm}$, but few oysters were found there. The composition of the subtidal epifaunal community varied seasonally but was dominated by the sponges Microciona prolifera (Ellis \& Solander) and Halichondria bowerbanki Burton. Barnacles B. eburneus and B. improvisus Darwin, tunicates Molgula manhattensis (DeKay), and unidentified bryozoans and hydroids were additional conspicuous macrofauna. Little free space was apparent and oysters were rare subtidally.

Physical data. Air and water temperature and salinity readings were recorded at $6 \mathrm{~min}$ intervals by automated sensors located approximately $30 \mathrm{~m}$ from the study site. The intertidal temperature range was measured at 1 to $3 \mathrm{~d}$ intervals with a minimum-maximum thermometer positioned at $+35 \mathrm{~cm}$ relative to MLW. Least-squares regression was used to evaluate linear trends of mean daily salinity and temperature with time. Hourly water heights were measured at the Gloucester Point National Oceanographic and Atmospheric Association tide station located $100 \mathrm{~m}$ from the study site. Percent aerial exposure at any given intertidal level was computed from these data and was resolved to a weekly scale. All tidal heights quoted in this report were referenced to the mean of the low water level of the river computed over an $18 \mathrm{yr}$ period from 1960 to 1978.

Early post-settlement mortality. Recruitment studies require clearly stated definitions of terms (Keough \& Downes 1982, Luckenbach 1984, Roegner 1991). Settlement for this study was defined as permanent cementation to the substrate. Post-settlement mortality was calculated from the proportion of individuals remaining from settlement over time scales of roughly 1 wk. Hence, a 'settler' was defined as a newly cemented individual, while a 'recruit' was a juvenile which had survived at least the first week of benthic existence. 'Recruitment' in this study thus included both the initial abundance of settlers and the subsequent survival of recruits. Oyster recruitment was measured at weekly intervals for $4 \mathrm{wk}$ post-settlement.

Experiments were initiated on 3 June, 8 July, and 9 September 1988 (spring, summer, and autumn experiments, respectively) and were terminated after 31,28 , and $28 \mathrm{~d}$, respectively. This period includes most of the natural settling period of oysters in this area (unpubl. technical reports, Virginia Oyster Spat Survey, VIMS, 1970-1990). The experimental design compared oyster survival at the tidal heights $+75,+50,+25,0(=\mathrm{MLW})$, -25 and $-75 \mathrm{~cm}$ relative to MLW. Unglazed $25 \mathrm{~cm}^{2}$ ceramic plates served as the settlement substrate. There were 10 replicate plates at each of the 6 tidal heights except in the spring experiment which used 7 plates at each of 5 heights $(-25 \mathrm{~cm}$ was not tested). Plates were pre-conditioned for $3 \mathrm{~d}$ in flowing York River water and then randomly sorted into 3 clear plastic containers filled with 51 of $5 \mu \mathrm{m}$ filtered York River water. Larvae were grown to the pediveliger (competent to settle) stage at the VIMS Oyster Hatchery and added to each container in approximately equal numbers. Salinity was ambient with river water (17 to $22 \%$ ), temperatures ranged between 20 and $24^{\circ} \mathrm{C}$, and the containers were shaded.

After a 3 to $5 \mathrm{~d}$ settlement period, the plates were removed from the containers and all individuals not firmly attached were displaced with a powerful jet of water. This insured that only oysters which had permanently cemented were counted as settlers. Settler density on the plates was nonuniform and varied over an order of magnitude within an experiment, and care was taken to standardise the settler density range among treatments. Density was measured by photo- 
graphing each plate on a copy stand with an Olympus OM camera fitted with a $50 \mathrm{~mm}$ macro lens at a 1:1.25 reproduction ratio. Photographs included a $1 \mathrm{~cm}^{2}$ internal scale which served both as a focusing reticule and for size determination of individual spat during data processing (see below). Individual plates required about $30 \mathrm{~s}$ for photography and were otherwise held submerged in flowing seawater.

After recording settler density, the plates were attached with plastic cable ties to a rectangular wood and plastic-coated wire rack $(2.5 \times 0.75 \mathrm{~m})$ and deployed into the York River on a permanent frame calibrated by tidal height. During subsequent sampling of recruits, the rack was brought into the laboratory and each plate was rephotographed as described, after which the rack was redeployed. Density of fouling organisms and evidence of predation were estimated during rack retrieval. Prior to photosampling, the plates were cleaned of all epibiota except the more tenacious serpulid worms and barnacles. This removal was necessary to have clear photographs of the juvenile oysters, but the cumulative effects of competition and predation on experimental oyster survival and growth were thus reduced compared to natural populations. The sampling procedure resulted in a time series of 5 photographs for each plate.

To determine recruitment, each time series was digitised and stored into a computerised image analyser (System 575, International Imaging Systems), and the images were then recalled in sequence to identify individual oysters. Mortality was conservatively determined as presence/absence from the initial photograph. Cumulative proportional mortality $(M p)$ at each date sampled was computed from the census data as $M p_{t}=1-\left(N_{t} / N_{1}\right)$, where $N$ is oyster density (no. plate $^{-1}$ ) and $t$ is oyster age (d). For each tidal height, the mean $M p$ was computed for the weekly sample intervals from the 10 replicate plates $(7$ in the spring experiment), but once the variance of a tidal height reached zero (all spat dead) it was removed from further analysis. A one-way ANOVA was used to test the null hypothesis of no difference in the arcsine-squareroot-transformed $M p$ among tidal levels at each age. Comparisons of $M p$ among intervals were not tested because of non-independence of replicate plates between sample dates. Bartlett's test was used to test for homogeneity of variances and Tukey's HSD test $(\alpha=0.05)$ was used when appropriate to distinguish significantly different groups.

Proportional daily mortality rate per plate $(Z p$, proportional mortality $\mathrm{d}^{-1}$ plate $\left.^{-1}\right)$ was computed for each weekly interval as $Z p_{t}=\left[1-\left(N_{t} / N_{t-1}\right)\right] / d t$, where $d t$ designates the time interval in days and the other symbols are as above. Least-squares regression was used to evaluate the linear trend in the log-transformed mean $Z p$ with time.
Size and growth. The size of individual Crassostrea virginica, measured as planar shell area $\left(\mathrm{mm}^{2}\right)$, was determined on the image analyser with a 'blotch' function which computed the number of pixels within an operator-defined area. Areas in the images were standardised to the $1 \mathrm{~cm}^{2}$ internal scale. For statistical comparisons, the mean oyster area was calculated after pooling the replicate plates by tidal level for each date sampled. For each experiment, a one-way ANOVA comparing mean area per tidal level for each weekly interval was used to test the hypothesis of no difference in size among levels. Tukey's HSD test $(\alpha=0.05)$ was used when appropriate to distinguish significantly different groups.

Growth was determined for individual oysters by the area difference between successive samples. Daily individual growth rates $\left(\mathrm{mm}^{2} \mathrm{~d}^{-1}\right)$ were computed for each weekly interval as $G a=\left(A_{t}-A_{t-1}\right) / d t$, where $A$ is oyster area $\left(\mathrm{mm}^{2}\right), t$ is sample interval, and $d t$ is duration (d) of the sample interval. The relation between log-transformed $G a$ and oyster age was investigated with least-squares regression.

Effect of density on growth. Due to the range of settler densities used in the experiments, we also investigated the effect of oyster density on growth by regressing the mean $G a$ plate $^{-1}$ over each sample interval by the no. of oysters plate ${ }^{-1}$ at the beginning of the sample interval. The expectation of growth reductions at high oyster densities should be evident as increasingly negative slopes of the regression lines with time (see Roegner 1991 for a similar analysis). Thus, changes in the slope of the growth-to-lagged-density regression lines over the course of an experiment were considered evidence for intraspecific competition.

\section{RESULTS}

\section{Physical data}

Mean salinity increased from about $17 \%$ in June to about $23 \%$ in October, with mean daily fluctuations of $<1$ to $5 \%$ (Fig. 1A). There was a significant increase in mean daily salinity with time during the spring $\left(\mathrm{p}<0.001, \mathrm{r}^{2}=0.890, \mathrm{n}=31\right)$ and summer $(\mathrm{p}<$ $0.001, r^{2}=0.235, n=29$ ) experiments but the mean salinity ranges over these periods were $<4 \%$. The autumn experiment exhibited no significant trend with time $\left(\mathrm{p}=0.535, \mathrm{r}^{2}=0.356 \mathrm{n}=29\right)$; the mean salinity range remained about $2 \%$. Salinities during the spring experiment ranged between 17 and $21 \%$, while salinities during the summer and autumn experiments were slightly higher (21 to $23 \%$ ). These values are well within the tolerance range of Crassostrea virginica. 

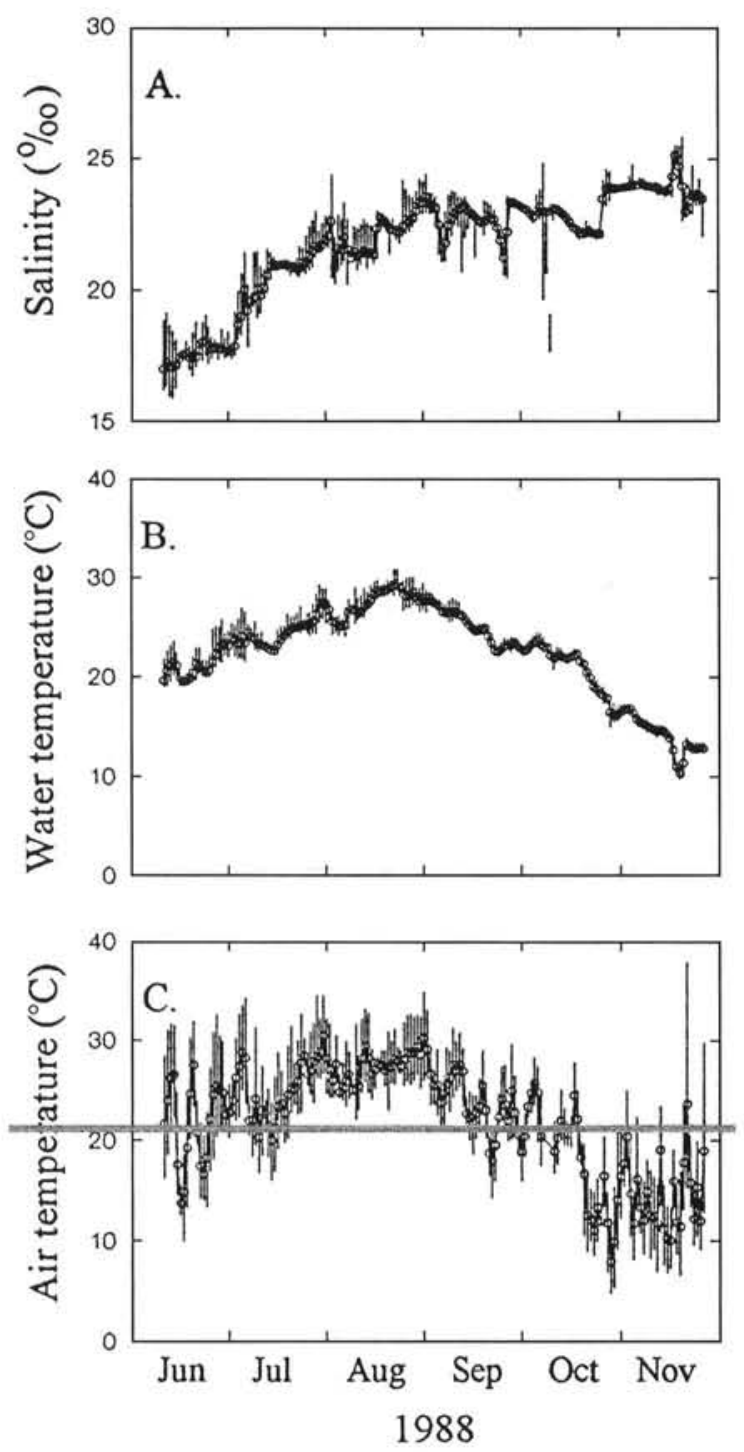

Fig. 1. (A) Mean salinity range, (B) mean water temperature range, and (C) mean air temperature range, during the experimental period

Mean daily water temperature during the experimental period ranged from approximately 20 to $30^{\circ} \mathrm{C}$, with a maximum reached during the summer experiment (Fig. 1B). Mean temperatures increased by 4 to $5^{\circ} \mathrm{C}$ during the spring and summer experiments and exhibited significant linear increases with time (spring: $\mathrm{p}<0.001, \mathrm{r}^{2}=0.564, \mathrm{n}=31$; summer: $\mathrm{p}<0.001, \mathrm{r}^{2}=$ $0.569, \mathrm{n}=29$ ). Mean water temperature significantly decreased from 24 to $19^{\circ} \mathrm{C}$ during the autumn $\left(\mathrm{p}<0.001, \mathrm{r}^{2}=0.601, \mathrm{n}=29\right)$. Throughout the experimental period, mean daily variation in water temperature was usually $<5^{\circ} \mathrm{C}$.

Mean daily air temperatures ranged from 18 to $31^{\circ} \mathrm{C}$ during the experimental period (Fig. 1C). During spring, the mean daily air temperatures ranged from 19 to $29^{\circ} \mathrm{C}$, with a third of the experimental period experiencing mean daily maximum temperatures $>30^{\circ} \mathrm{C}$. The range of mean daily temperatures during summer was 25 to $31^{\circ} \mathrm{C}$, with $57 \%$ of the days having maximum temperatures $>30^{\circ} \mathrm{C}$. No linear trend was observed with time in spring or summer (spring: $p=$ $0.512, \mathrm{r}^{2}=0.015, \mathrm{n}=31$; summer: $\mathrm{p}=0.890, \mathrm{r}^{2}=0.001$ ， $\mathrm{n}=29$ ). In contrast, mean daily air temperatures significantly decreased from 26 to $18^{\circ} \mathrm{C}$ during autumn, $\left(\mathrm{p}<0.001, \mathrm{r}^{2}=0.350, \mathrm{n}=29\right.$ ), with no days experiencing mean daily maximum temperatures $>30^{\circ} \mathrm{C}$.

Maximum intertidal temperatures measured at $+35 \mathrm{~cm}$ correlated with the mean daily maximum air temperatures $\left(\mathrm{p}=0.001, \mathrm{r}^{2}=0.805, \mathrm{n}=120\right)$, but were generally higher. In spring 12 out of 15 recorded days had air temperatures $>30^{\circ} \mathrm{C}$, with a maximum of $35^{\circ} \mathrm{C}$. In summer 16 of 18 recordings exceeded $30^{\circ} \mathrm{C}$ with half of those $>35^{\circ} \mathrm{C}$. In autumn, only 2 of 17 readings exceeded $30^{\circ} \mathrm{C}$.

Percent aerial exposure by tidal level was similar in spring and autumn, while the summer experiment exhibited $>15 \%$ increase in exposure between some levels (Table 1). This was due to the lower water levels in the York River during summer. Overall, the average experimental exposures were 80 to $90 \%$ at $+75 \mathrm{~cm}$, 50 to $65 \%$ at $+50 \mathrm{~cm}, 25$ to $45 \%$ at $+25 \mathrm{~cm}, 1$ to $10 \%$ at MLW, and the levels $<$ MLW were subtidal. Weekly differences in the percent exposure were relatively large, however, with changes of $>10 \%$ occurring between consecutive weeks.

\section{Post-settlement mortality}

Oyster mortality was high in the first week postsettlement at all tidal heights in each experiment, with

Table 1 . Weekly percent aerial exposure by tidal level. All heights $<$ MLW are subtidal

\begin{tabular}{|c|c|c|c|c|c|}
\hline \multirow[t]{2}{*}{ Expt } & \multirow{2}{*}{$\begin{array}{c}\text { Tidal } \\
\text { level }(\mathrm{cm})\end{array}$} & \multicolumn{4}{|c|}{ Week } \\
\hline & & 1 & 2 & 3 & 4 \\
\hline \multirow[t]{4}{*}{ Spring } & +75 & 73.4 & 94.8 & 89.6 & 80.7 \\
\hline & +50 & 46.3 & 64.0 & 59.2 & 57.8 \\
\hline & +25 & 24.5 & 38.5 & 27.9 & 36.5 \\
\hline & MLW & 4.7 & 2.1 & 1.7 & 3.7 \\
\hline \multirow[t]{4}{*}{ Summer } & +75 & 92.2 & 99.0 & 89.1 & 80.2 \\
\hline & +50 & 63.0 & 75.0 & 65.1 & 58.9 \\
\hline & +25 & 40.1 & 47.4 & 38.0 & 41.2 \\
\hline & MLW & 6.8 & 9.4 & 5.2 & 9.9 \\
\hline \multirow[t]{4}{*}{ Autumn } & +75 & 85.2 & 86.3 & 75.6 & 62.9 \\
\hline & +50 & 59.4 & 60.2 & 50.0 & 42.7 \\
\hline & +25 & 32.8 & 30.7 & 29.7 & 16.7 \\
\hline & MLW & 1.0 & 1.0 & 2.1 & 0.0 \\
\hline
\end{tabular}


settlers at +50 and $+75 \mathrm{~cm}$ incurring $100 \%$ mortality during this initial period (Fig. 2). At $+25 \mathrm{~cm}$ ( $>10 \%$ emersed), all oysters died within 2 wk with the exception of the autumn experiment, when survival was relatively good (see below). The mean percentage of the settler population which died each day $(Z p)$ ranged from 14.3 to $9.3 \% \mathrm{~d}^{-1}(M p=100$ and $64.2 \%$ $\mathrm{d}^{-1}$, respectively), while recruit $Z p$ fell below $1.0 \% \mathrm{~d}^{-1}$ after the second week. Regression analysis indicated $Z p$ declined significantly with time for all treatments (Table 2). Thus, while most newly settled oysters did not survive the first week of post-settlement life, the subsequent recruit mortality was low.

The time course of recruitment varied among experiments. During spring, settler mortality was significantly lower at MLW than at $-75 \mathrm{~cm}$ or $+25 \mathrm{~cm}$ (Fig. 2A, Table 3). At MLW, significantly higher survival persisted through the second week, after which cumulative mortality was not significantly different from oysters at $-75 \mathrm{~cm}$ (88.7 and $94.2 \%$, respectively).

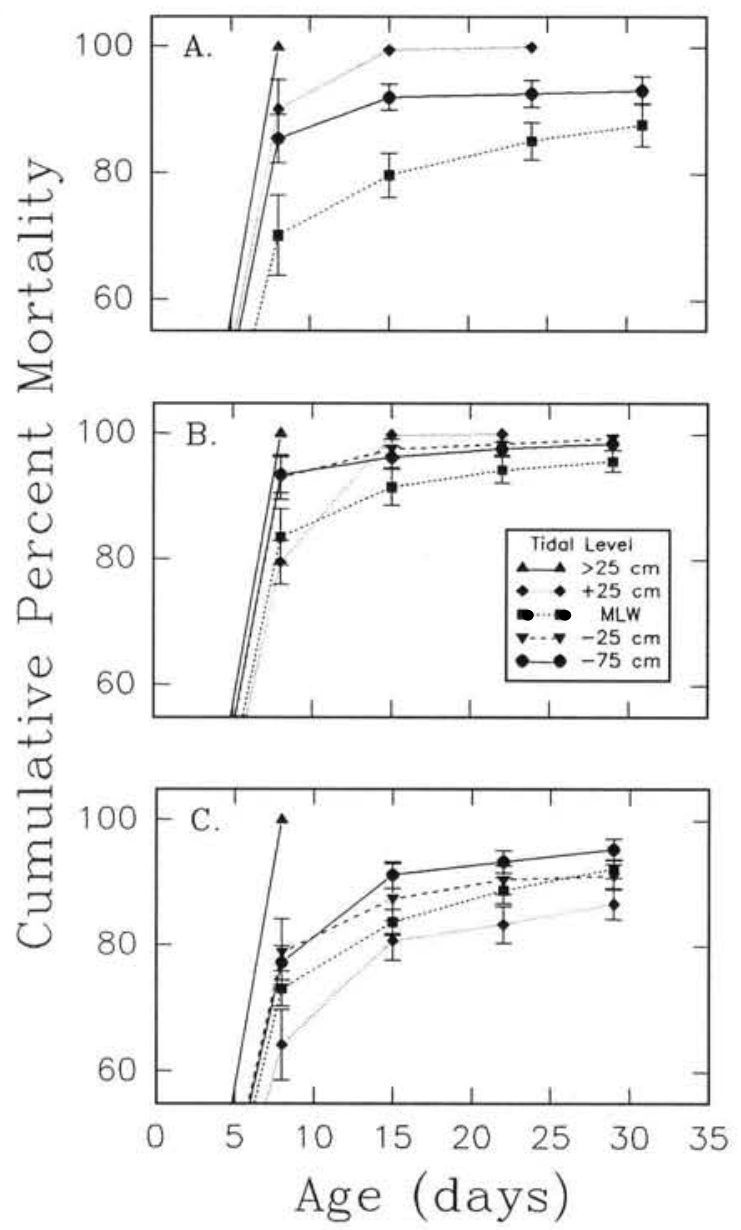

Fig. 2. Crassostrea virginica. Mean cumulative percent mortality $( \pm \mathrm{SE})$ by oyster age for each tidal treatment in (A) spring, (B) summer, and (C) autumn
The summer experiment had a similar pattern except settler survival at $+25 \mathrm{~cm}$ was significantly higher than at $-75 \mathrm{~cm}$ (Fig. 2B, Table 3); however, during the following week mortality of recruits at $+25 \mathrm{~cm}$ was nearly complete. The MLW, -25 , and $-75 \mathrm{~cm}$ levels did not show further significant differences in cumulative mortality. Survival was very low, with final mortalities ranging from 93 to $99 \%$. Intertidal recruitment was comparatively more successful in the autumn (Fig. 2C, Table 3). After the first week, settler survival was relatively high ( 22 to $35 \%$ ) and was not significantly different between +25 , MLW,-25 and $-75 \mathrm{~cm}$ levels. Over each of the next 3 weeks, there was significantly lower mortality at $+25 \mathrm{~cm}$ relative to $-75 \mathrm{~cm}$ level. No other significant differences were detected. Final mean mortalities ranged from 87 to $95 \%$. Thus, in contrast to the earlier experiments, there was a substantial recruitment into the mid-intertidal zone in autumn.

\section{Size and growth}

Shell areas of juvenile oysters increased between 2 and 3 orders of magnitude during each of the monthlong experiments (Fig. 3). Regressions of log-transformed individual daily growth rates $(G a)$ of oysters exhibited significant positive increases with time for treatments with surviving recruits (Table 4). In general, growth differences were most pronounced between mid-intertidal oysters and those grown at $-75 \mathrm{~cm}$; fluctuations among the weekly growth rates resulted in inconsistent statistical results among the MLW and subtidal treatments (see below).

During spring, the mean daily growth rates and sizes were consistently greater subtidally than in the intertidal zone (Fig. 3A, Tables 4 \& 5). After the second week, oysters at MLW grew only about $50 \%$ as large as those at $-75 \mathrm{~cm}$. After the first week of the summer experiment, shell areas at +25 , MLW, -25 , and $-75 \mathrm{~cm}$ were all significantly different from each other, with the highest growth at MLW (Fig. 3B, Tables 4 \& 5). Again, oysters at $+25 \mathrm{~cm}$ grew only marginally before complete mortality occurred. After the second week, oysters at MLW exhibited a very high relative $G a$ and were significantly larger than oysters at the subtidal stations. However, no significant difference in size among treatments was found at the third week and there was a greater mean size at $-75 \mathrm{~cm}$ after $4 \mathrm{wk}$ (Table 5). During autumn, survival at $+25 \mathrm{~cm}$ was relatively good but growth was consistently less than at the more immersed treatments, and mean sizes lagged about a week behind the lower levels (Fig. 3C, Tables 4 \& 5). The statistical significance of the weekly size ANOVA and Tukey HSD differed due to varied $G a$, although $-75 \mathrm{~cm}$ was always in the fastest growing group. 
Table 2. Crassostrea virginica. Mean percent daily mortality rate $(Z p \times 100)$ for each tidal level, week, and season combination. Statistical values for regression of $Z p$ by time for each combination of tidal level and season are also given. Slopes of all regression lines are negative. $n$ : number of plates; nd: not done; -: all oysters dead

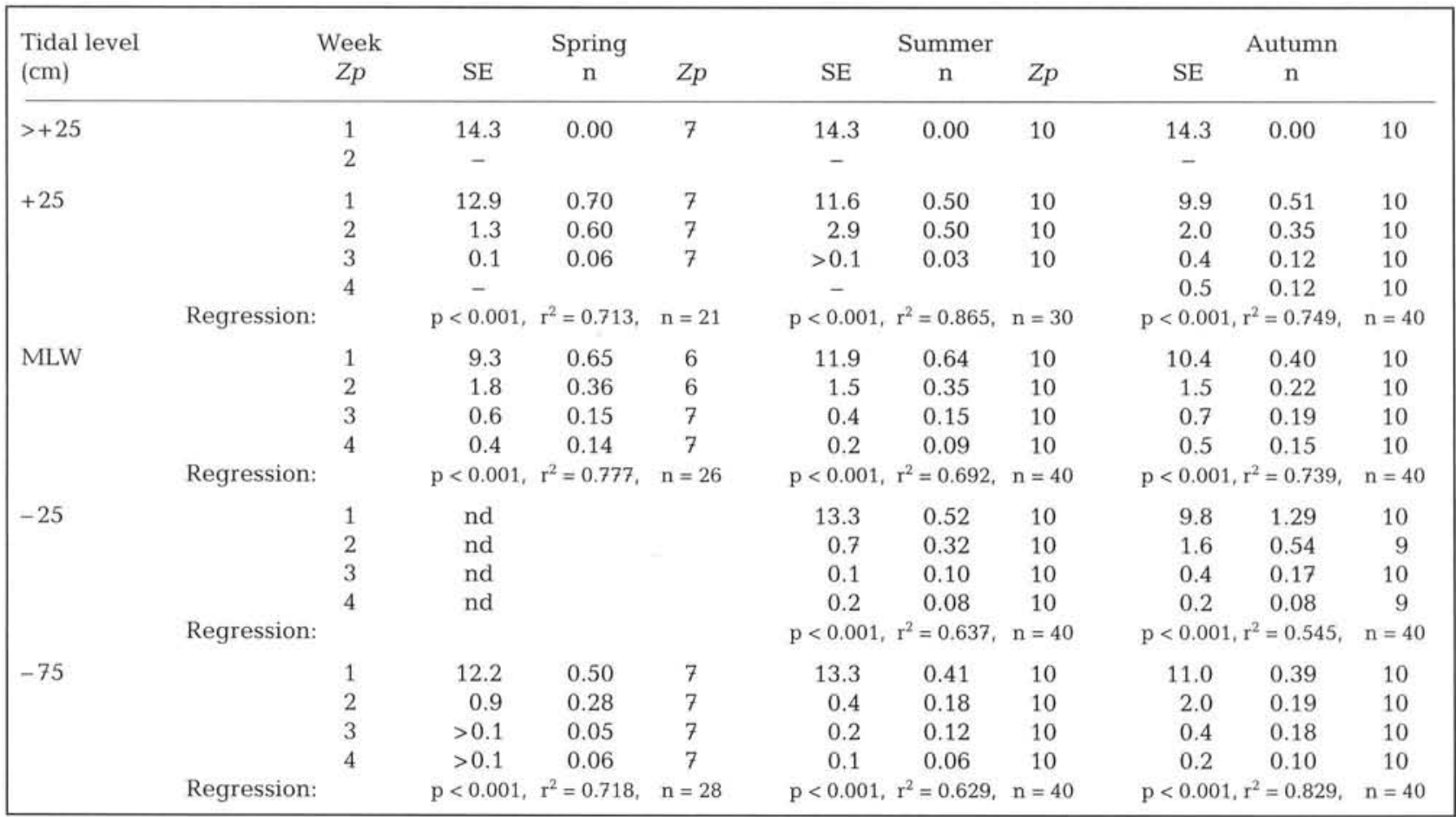

\section{Effect of density on growth}

There were no significant regressions between mean daily growth rate plate ${ }^{-1}$ and the lagged oyster density for any experiment-treatment combination. Oysters on

Table 3. Crassostrea virginica. ANOVA and Tukey's HSD test comparing oyster proportional mortality by treatment for each weekly sample interval. For the Tukey's test, the relative order from lowest to highest mortality of significantly different groups is shown, while parentheses enclose groups which were not different. $1:+25 \mathrm{~cm} ; 2:$ MLW; $3:-25 \mathrm{~cm}$; $4:-75 \mathrm{~cm} . \mathrm{ns}$ : not significantly different

\begin{tabular}{|lrrrl|}
\hline \multirow{2}{*}{ Expt } & Week & \multicolumn{2}{c|}{ ANOVA } & \multicolumn{1}{c|}{ Tukey's test } \\
& \multicolumn{1}{c}{$\mathrm{p}$} & $\mathrm{df}$ & \\
\hline Spring & 1 & 0.007 & 19 & $2<(4=1)$ \\
& 2 & $>0.001$ & 19 & $2<4<1$ \\
& 3 & 0.050 & 13 & $\mathrm{n}$ \\
& 4 & 0.153 & 13 & $\mathrm{~ns}$ \\
Summer & 1 & 0.017 & 37 & $1<4 ;(1=2=3,2=3=4)$ \\
& 2 & 0.020 & 37 & $2<1 ;(1=3=4,2=3=4)$ \\
& 3 & 0.241 & 37 & $\mathrm{~ns}$ \\
& 4 & 0.132 & 36 & $\mathrm{~ns}$ \\
Autumn & 1 & 0.152 & 37 & $\mathrm{~ns}$ \\
& 2 & 0.012 & 36 & $1<4 ;(1=2=3,2=3=4)$ \\
& 3 & 0.020 & 36 & $1<4 ;(1=2=3,2=3=4)$ \\
& 4 & 0.011 & 38 & $1<4 ;(1=2=3,2=3=4)$ \\
\hline
\end{tabular}

plates with high densities did not have lower growth rates, suggesting that intraspecific competition due to crowding was not affecting oyster growth over the time periods investigated.

\section{DISCUSSION}

\section{Recruitment}

The pronounced mortality of newly settled oysters constituted the most important event structuring the population during the early recruitment period at this site. Of the settlers which successfully cemented to the plates, 64 to $100 \%$ were dead after $1 \mathrm{wk}$. Such high initial mortality has been alluded to in previous studies of oysters (Chestnut \& Fahy 1952, Andrews 1954, Hopkins 1954, MacKenzie 1970, 1981, Michener \& Kenny 1991), as well as in recruitment studies with other species (e.g. Keough \& Downes 1982, Luckenbach 1984). The cause of settler mortality in the present study was largely undetermined. However, the losses were density-independent, and occurred before strong competition from fouling organisms was possible (Roegner 1991). MacKenzie (1981) attributed 'early post-setting mortality' to a physiological defect, while Chestnut \& Fahy (1952) and Michener \& Kenny (1991) considered 


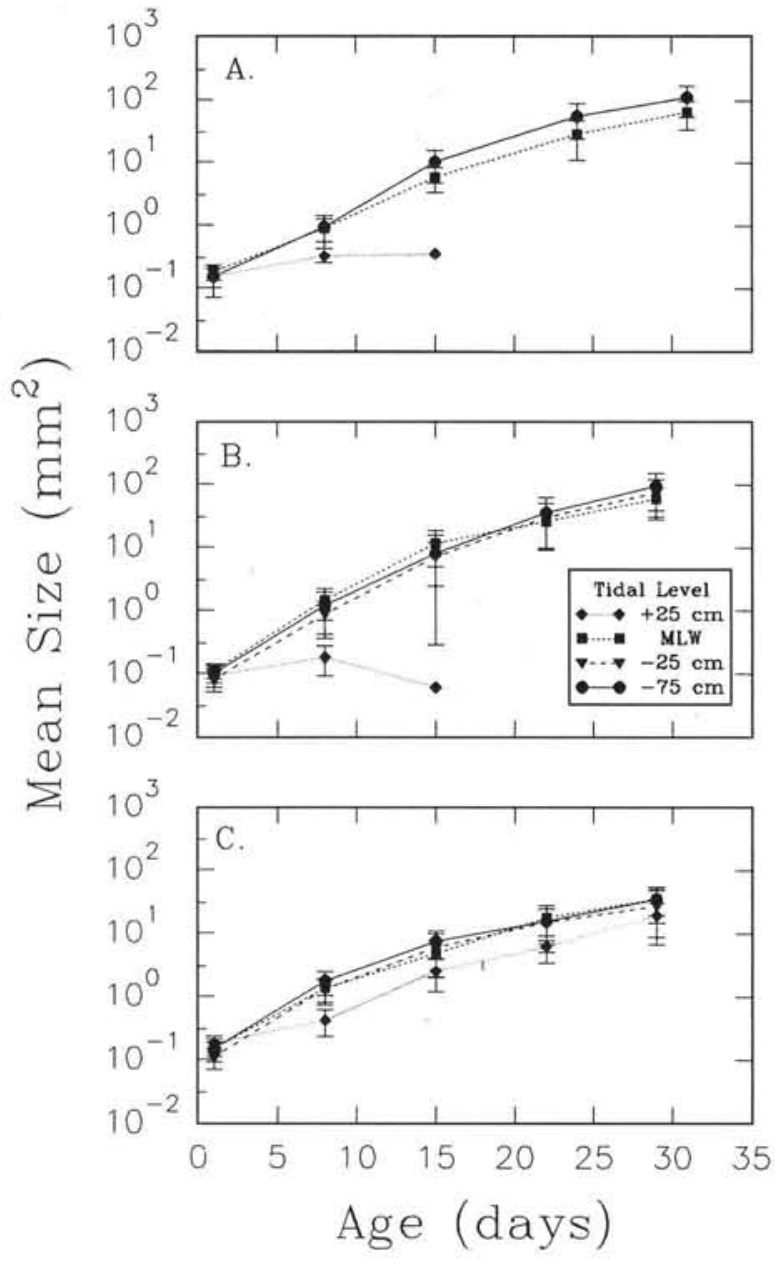

Fig. 3. Crassostrea virginica. Mean size $\left(\mathrm{mm}^{2} \pm \mathrm{SE}\right)$ by oyster age for each tidal treatment in (A) spring, (B) summer, and (C) autumn

the greater values of cumulative recruitment in shortperiod samples compared to those from longer periods as a predation effect. The pervasive settler mortality found across all tidal heights and experiments in this study suggests an internal (metabolic) rather than external cause.

Exposure exerted an additional mortality on intertidal oysters. The magnitude of the effect varied by immersion period and seasonal air temperature. Oysters placed at MLW, with aerial exposures $<10 \%$, never exhibited significant reductions in recruitment over subtidal treatments, and often had increased comparative survival (which may be related to negative competitive interactions in the subtidal zone). In contrast, recruitment above MLW was severely curtailed until aerial temperatures fell below $30^{\circ} \mathrm{C}$ in autumn. No oysters recruited into upper intertidal levels $(+50$ and $+75 \mathrm{~cm}$ ) during any of the experimental periods and in the spring and summer even moderate expo- sures at $+25 \mathrm{~cm}$ resulted in complete mortalities of experimental oysters as well as natural barnacle settlers. In contrast, during the autumn experiment, when air temperatures generally remained below $30^{\circ} \mathrm{C}$, there was a significant survival of oysters in the midintertidal zone, as well as an upward range extension of fouling organisms. Observations indicated natural intertidal recruitment of oysters onto the pier pilings also occurred only in September and October. Exposure stress leading to desiccation (due to excessive heat, evaporative losses, and respiratory inhibition) has long been implicated in reducing the upper zonation of intertidal organisms (Newell 1979), including oysters (Nichy \& Menzel 1967, Bahr \& Lanier 1981, Potter \& Hill 1982, Michener \& Kenny 1991), and likely explains the additional high mortality in the intertidal treatments. Nichy \& Menzel (1967) recorded high mortalities of older oysters when internal temperatures exceeded $35^{\circ} \mathrm{C}$. Small, recently settled oysters would be particularly vulnerable to desiccation.

In contrast to the effects of exposure time and aerial temperature, the ranges of water temperature and salinities encountered during this study were well within the tolerance limits of oysters (Galtsoff 1964). It is difficult to ascertain the seasonal difference in Crassostrea virginica survival or growth rates due to the unmeasured genetic qualities of the cohorts (Newkirk et al. 1977, Losee 1979, Paynter \& DiMichele 1990), as well as variations in food resources (Utting 1988), although the diminishing water temperatures during the autumn experiment may have contributed to the lower overall growth rates during this period (Dame 1972). However, the salinity regime had an indirect control by supporting oyster predators such as the gastropods Eupleura caudata Say and Urosalpinx cinerea Say, the blue crab Callinectes sapidus Rathbun, and the flatworm Stylochus ellipticus (Girard). These predators have well-known impacts on oysters (Chestnut \& Fahy 1952, Mackin 1959, Nichy \& Menzel 1967. MacKenzie 1970, Kranz \& Chamberlin 1978) and were directly observed to cause mortality of subtidal spat in this study.

The population dynamics of newly settled Crassostrea virginica in relation to tidal zonation in the York River resembles that from other studies conducted over a variety of temporal scales and post-settlement ages. Loosanoff (1932) monitored recruitment along the tidal gradient in the James and Corrotoman Rivers, Chesapeake Bay, and found the best survival near the bottom and good survival intertidally. In the higher salinity site at Wachapreague, Virginia, however, most survival was intertidal due to gastropod predation below MLW. The sample periods of these studies ranged from 3 to $3.5 \mathrm{mo}$, and thus measured cumulative recruitment. Mackin (1946), repeating this work at Wacha- 
Table 4. Crassostrea virginica. Mean daily growth rate $(G a)$ for each tidal level, week, and season combination. Statistical values for regression of $\mathrm{Ga}$ by time for each tidal level-season combination are also given. Slopes of all regression lines are positve. $\mathrm{n}$ : number of spat; nd: not done; -: all oysters dead at end of week

\begin{tabular}{|c|c|c|c|c|c|c|c|c|c|c|}
\hline \multirow[t]{2}{*}{ Tidal level $(\mathrm{cm})$} & \multirow[t]{2}{*}{ Week } & \multicolumn{3}{|c|}{ Spring } & \multicolumn{3}{|c|}{ Summer } & \multicolumn{3}{|c|}{ Autumn } \\
\hline & & $G a$ & SE & $\mathrm{n}$ & Ga & SE & $\mathrm{n}$ & $G a$ & SE & $\mathrm{n}$ \\
\hline$>+25$ & 1 & - & & & - & & & - & & \\
\hline \multirow[t]{5}{*}{+25} & 1 & 0.02 & 0.01 & 16 & 0.01 & 0.01 & 267 & 0.04 & 0.01 & 238 \\
\hline & 2 & 0.01 & & 1 & - & & & 0.26 & 0.02 & 144 \\
\hline & 3 & - & & & - & & & 0.54 & 0.03 & 141 \\
\hline & 4 & - & & & - & & & 1.86 & 0.13 & 110 \\
\hline & & $\mathrm{p}=0.035$ & $r^{2}=0.299$ & $\mathrm{n}=15$ & & & & $\mathrm{p}<0.00$ & ${ }^{2}=0.673$, & $\mathrm{n}=601$ \\
\hline \multirow[t]{5}{*}{ MLW } & 1 & 0.01 & 0.01 & 205 & 0.22 & 0.01 & 100 & 0.17 & 0.01 & 405 \\
\hline & 2 & 0.53 & 0.03 & 120 & 1.45 & 0.08 & 128 & 0.48 & 0.03 & 243 \\
\hline & 3 & 3.15 & 0.27 & 76 & 1.95 & 0.24 & 69 & 1.83 & 0.12 & 142 \\
\hline & 4 & 5.05 & 0.58 & 52 & 4.78 & 0.63 & 47 & 2.55 & 0.29 & 97 \\
\hline & & $\mathrm{p}<0.001$, & $\mathrm{r}^{2}=0.755$ & $\mathrm{n}=480$ & $\mathrm{p}<0.001$, & $r^{2}=0.54$ & $\mathrm{n}=328$ & $\mathrm{p}<0.00$ & ${ }^{2}=0.571$, & $\mathrm{n}=855$ \\
\hline \multirow[t]{5}{*}{-25} & 1 & nd & & & 0.11 & 0.01 & 149 & 0.17 & 0.01 & 162 \\
\hline & 2 & nd & & & 0.87 & 0.09 & 55 & 0.70 & 0.06 & 99 \\
\hline & 3 & nd & & & 3.08 & 0.52 & 32 & 1.43 & 0.16 & 60 \\
\hline & 4 & nd & & & 5.19 & 1.87 & 13 & 1.96 & 0.29 & 57 \\
\hline & & & & & $\mathrm{p}<0.001$ & $r^{2}=0.73$ & $\mathrm{n}=243$ & $\mathrm{p}<0.00$ & ${ }^{2}=0.464$, & $\mathrm{n}=361$ \\
\hline \multirow[t]{5}{*}{-75} & 1 & 0.11 & 0.01 & 53 & 0.21 & 0.10 & 132 & 0.23 & 0.01 & 220 \\
\hline & 2 & 1.28 & 0.14 & 29 & 0.95 & 0.09 & 145 & 0.80 & 0.05 & 102 \\
\hline & 3 & 6.31 & 0.78 & 25 & 3.18 & 0.34 & 87 & 1.21 & 0.16 & 63 \\
\hline & 4 & 7.59 & 1.08 & 22 & 6.97 & 1.06 & 41 & 2.84 & 0.49 & 40 \\
\hline & & $\mathrm{p}<0.001$, & $r^{2}=0.723$ & $\mathrm{n}=145$ & $\mathrm{p}<0.001$ & $r^{2}=0.58$ & $\mathrm{n}=368$ & $\mathrm{p}<0.00$ & ${ }^{2}=0.544$, & $\mathrm{n}=408$ \\
\hline
\end{tabular}

preague over periods between 1 and $4 \mathrm{mo}$, found comparable results. Growth intertidally was found to decrease with exposure time, while predator activity was sharply increased below MLW. In Beaufort, North Carolina, USA, McDougall (1942) monitored the settlement of organisms on cleaned plates at 1 to $2 \mathrm{wk}$ intervals as well as recruitment of organisms on uncleaned plates every $2 \mathrm{wk}$. All unprotected subtidal oysters were killed, presumably through competitive interactions (Urosalpinx cinerea and Cliona sp. were absent), while intertidal oysters survived. Ortega (1981) compared the intertidal distributions of fouling organisms between protected and wave-exposed sites in Beaufort. Oysters were out-competed by the mussel Brachidontes exustus (Linnaeus) at the exposed sites due to differential tolerance to wave stress. $C$. virginica dominated at protected sites because of higher recruitment and faster growth rates. Predation was found to be unimportant to the structuring of the intertidal communities because predatory gastropods were not active in the intertidal zone. Chestnut \& Fahy (1952) also attributed predation and competition to the prevalence of intertidal oysters in Bogue Sound, North Carolina. In Georgia, USA, Bahr \& Lanier (1981) concluded that boring sponges caused the high subtidal mortality and considered growth orientations which afforded mutual shading to be important for reducing heat mortality in the intertidal zone. In Florida, USA, Nichy \& Menzel
(1967) concluded that the intertidal distribution of oysters was maintained by heat mortality at the upper levels and by predation subtidally. Our study demonstrated the impact of settler mortality and intertidal exposure stress on oyster distribution during the first month of benthic life.

Table 5. Crassostrea virginica. ANOVA and Tukey's HSD test comparing oyster size by treatment for each weekly sample interval. For Tukey's test, the relative order from smallest to largest of significantly different groups is shown, while parentheses enclose groups which were not different. 1: $+25 \mathrm{~cm} ; 2$ : MLW; $3:-25 \mathrm{~cm} ; 4:-75 \mathrm{~cm}$. ns: not significantly different

\begin{tabular}{|lrrrl|}
\hline \multirow{2}{*}{ Expt } & \multirow{2}{*}{ Week } & \multicolumn{2}{c}{ ANOVA } & Tukey's test \\
& & \multicolumn{1}{c}{$\mathrm{p}$} & $\mathrm{df}$ & \\
\hline Spring & 1 & 0.002 & 278 & $(1=4)<2$ \\
& 2 & $>0.001$ & 274 & $1<2<4$ \\
& 3 & $>0.001$ & 101 & $2<4$ \\
& 4 & $>0.001$ & 73 & $2<4$ \\
Summer & 1 & $>0.001$ & 1008 & $1<3<4<2$ \\
& 2 & $>0.001$ & 325 & $(3=4)<2$ \\
& 3 & 0.118 & 185 & $\mathrm{~ns}$ \\
Autumn & 4 & 0.001 & 98 & $2<4$ \\
& 1 & $>0.001$ & 1051 & $1<(2=3)<4$ \\
& 2 & $>0.001$ & 612 & $1<2<3<4$ \\
& 3 & $>0.001$ & 403 & $1<(2=3=4)$ \\
& 4 & $>0.001$ & 300 & $1<3<(2=4)$ \\
\hline
\end{tabular}




\section{Growth}

Oyster growth in the mid-intertidal zone was retarded in comparison to subtidal treatments. In spring and summer, mean daily growth rates at $+25 \mathrm{~cm}$ level were 10 to $25 \%$ lower than that of the more immersed treatments before mortality occurred. During autumn, mid-intertidal oysters grew about $50 \%$ slower than oysters at the low-shore treatments. The lower growth in the intertidal may reflect the consequences of reduced feeding times (Peterson \& Black 1987 ) or metabolic stress associated with emergence (Dame 1972, Newell 1979). Dame (1972) showed oysters increase oxygen consumption with increasing temperatures, while Koehn \& Shumway (1982) attributed efficient oxygen utilisation rates to increased oyster growth. Energy in mid-intertidal spat may have been used for metabolic maintenance, thus reducing the amount available for somatic growth.

The effect of exposure on growth at MLW was not consistent. During the spring, with exposures ranging from 1.7 to $4.7 \%$, the mean daily growth rate at MLW was about $50 \%$ that at $-75 \mathrm{~cm}$ and the final mean oyster size was significantly less in the intertidal zone. In contrast, during the higher aerial exposures (5.2 to $9.9 \%$ ) and temperatures in the summer experiment, oysters at MLW exhibited comparatively rapid growth rates relative to oysters at the subtidal treatments during the first $2 \mathrm{wk}$ but lower growth rates subsequently. Final sizes at MLW were again significantly smaller than oysters at $-75 \mathrm{~cm}$, while no difference was detected with those at $-25 \mathrm{~cm}$. This pattern was reversed in autumn (aerial exposures 0 to $2.1 \%$, lower air temperatures), when oyster $G a$ at MLW was initially lower than $G a$ at the subtidal treatments, but increased during the second $2 \mathrm{wk}$ so that after $4 \mathrm{wk}$ no difference was detected between mean area of oysters at MLW and $-75 \mathrm{~cm}$, although both were again significantly larger than oysters at $-25 \mathrm{~cm}$. Thus, there was no conclusive evidence for negative effects of aerial exposure on oyster growth at low levels of emersion.

There are few experimental studies which quantify growth of Crassostrea virginica in relation to tidal zonation over the early recruitment period, but the comparable investigations generally report intertidal growth reductions. Loosanoff (1932) found intertidal oysters to be smaller than subtidal oysters after a 3.5 mo recruitment period in the James River, Virginia, although he attributed this to later settlement of the intertidal oysters. Ingle \& Dawson (1952) found diminished growth rates in exposed oysters and no difference in growth rates of oysters placed at different subtidal depths in Florida. Gillmor (1982) grew oysters (10 to $20 \mathrm{~mm}$ shell height) at 0,20,40 and $60 \%$ emersion levels in laboratory and field experiments and sug- gested enhanced intertidal growth was due to an energy 'compensatory' mechanism. However, the rationale for a curvilinear fit to essentially linear field growth data coupled with the poor growth performance of the laboratory stock makes this conclusion equivocal. Crosby et al. (1991) followed the growth of recently settled ( 1 to $13 \mathrm{~d}$, mean size $1.3 \mathrm{~mm}$ ) C. virginica for $7 \mathrm{wk}$ and measured greater mean cumulative growth rates for subtidal oysters than those exposed at the $20 \%$ level until a post-settlement age of about $34 \mathrm{~d}$, after which no significant difference was detected. As a result of shorter immersion periods, intertidal oysters required an additional $22 \mathrm{~d}$ to reach the same size as subtidal oysters. In the present study, we found clear reductions in growth at exposure levels $>25 \%$, with a variable response at the 1 to $10 \%$ levels of emersion for up to $30 \mathrm{~d}$ post-settlement.

Growth in other species of oysters has also been compared along the tidal gradient. Spencer \& Gough (1978) found little overall difference between the growth or survival of Crassostrea gigas Thunberg or Ostrea edulis L. held subtidally from rafts versus intertidal trays subjected to low levels of emersion $(5 \%)$. Roland \& Albrecht (1986) measured reduced growth rates of C. gigas at $+2.1 \mathrm{~m}$ compared with +0.9 to $1.2 \mathrm{~m}$, while Sumner (1981) similarly found higher growth in subtidally grown oysters over $3 \mathrm{mo}$. Walne (1958) demonstrated reduced growth rate with intertidal height with $O$. edulis in Conway, Great Britain. Wisely et al. $(1979 \mathrm{a}$, b) found subtidal growth of $C$. commercialis to be 3 times that of oysters at the mid tide level in Australia. Littlewood (1988), working with C. rhizophorae in Jamaica, documented reductions in growth parameters between the 36 to $98 \%$ exposure levels relative to oysters in the low intertidal zone (10 to $17 \%$ exposed) or subtidal zone. Oysters exposed 1 to $3 \%$ of the time (Littlewood's levels 7 to 9 ), however, exhibited some growth reductions relative to the $17 \%$ exposure level, but not to the subtidal treatment. The data seem to show few differences in growth parameters below about $36 \%$ aerial exposure. It is evident that for the oyster species investigated growth is reduced at high levels of aerial exposure while short exposures can have either positive or negative effects.

In conclusion, the use of hatchery-reared larvae allowed a clear determination of the time course of growth and mortality of Crassostrea virginica during the early recruitment period. Early post-settlement mortality strongly influenced oyster demography. High settler mortality rapidly decreased oyster abundance across all tidal heights, and an additional exposurerelated mortality of early recruits controlled the timing of oyster recruitment above the low intertidal zone. Subsequent mortality rates of recruits declined sharply, indicating recruitment into the population was 
constrained by the survival of settlers and $1 \mathrm{wk}$ old recruits. The mid-intertidal area occupied by the resident adult oysters was successfully colonised only in the autumn experiment, when aerial temperatures were decreasing, while subtidal oysters persisted during the monthly time scale of the experiments at levels which were probably inflated by removal of predators and epibionts during sampling. In addition, growth was substantially reduced at the $25 \%$ exposure level compared to more immersed treatment levels. The fact that intertidal survival was not possible until aerial temperatures were reduced suggests that successful recruitment into the intertidal population was limited to a relatively short environmental window by early post-settlement mortality.

Acknowledgements. We thank the staff of the VIMS Oyster Hatchery for supplying pediveligers. Subroutine programs used with the image analyser were written by K. Kiley. The original manuscript was improved by the constructive comments of C. Emerson and 3 anonymous referees. This work forms part of the Master's thesis of G.C.R. from the College of William and Mary. Contribution number 1886 from the Virginia Institute of Marine Science.

\section{LITERATURE CITED}

Andrews, J. D. (1954). Setting of oysters in Virginia. Proc. natn. Shellfish. Ass. 54: 38-46

Bahr, L. M., Lanier, W. P. (1981). The ecology of intertidal oyster reefs in the South Atlantic: a community profile. FWS/OBS-81/15. U.S. Fish and Wildlife Service, Office of Biological Services, Washington, DC

Chestnut, A. F., Fahy, W. E. (1952). Studies on the setting intensity of oysters in Bogue Sound, North Carolina. Proc. natn. Shellfish. Ass. 43: 79-89

Connell, J. H. (1985). The consequences of variation in initial settlement vs. post- settlement mortality in rocky intertidal communities. J. exp. mar. Biol. Ecol. 93: 11-45

Crosby, M. P., Roberts, C. F., Kenny, P. D. (1991). Effects of immersion time and tidal position on in situ growth rates of naturally settled eastern oysters, Crassostrea virginica (Gmelin, 1791). J. Shellfish Res. 10: 95-103

Dame, R. F. (1972). The ecological energetics of growth, respiration and assimilation in the intertidal American oyster, Crassostrea virginica. Mar. Biol. 17: 243-250

Gaines, S., Roughgarden, J. (1985). Larval settlement rate: a leading determinant of structure in an ecological community of the marine intertidal zone. Proc. Natl Acad. Sci. U.S.A. $82: 3707-3711$

Galtsoff, P. S. (1964). The American oyster, Crassostrea virginica (Gmelin). U.S. Fish Wild. Bull. No. 64

Galtsoff, P. S., Luce, R. H. (1930). Oyster investigations in Georgia. U.S. Bur. Fisheries Doc. 1077: 61-100

Gillmor, R. B. (1982). Assessment of intertidal growth and capacity adaptions in suspension-feeding bivalves. Mar. Biol. 68: 277-286

Hopkins, S. H. (1954). Oyster setting on the Gulf Coast. Proc. natn. Shellfish. Ass. 45: 52-55

Ingle, R. M., Dawson, C. E. Jr (1952). Growth of the American oyster Crassostrea virginica (Gmelin) in Florida waters. Bull. mar. Sci. Gulf Caribb. 2: 393-404

Keough, M. J., Downes, B. J. (1982). Recruitment of marine invertebrates. The role of active larval choices and early mortality. Oecologia 54: 348-352

Koehn, R. K., Shumway, S. E. (1982). A genetic/physiological explanation for differential growth rate among individuals of the American oyster Crassostrea virginica (Gmelin). Mar. Biol. Lett. 3: 35-42

Kranz, G. E., Chamberlin, J. V. (1978). Blue crab predation on cultchless oyster spat. Proc. natn. Shellfish. Ass. 68: $38-41$

Littlewood, D. T. J. (1988). Subtidal versus intertidal cultivation of Crassostrea rhizophorae. Aquaculture 72: 59-71

Loosanoff, V. L. (1932). Observations on propagation of oysters in James and Corrotoman Rivers and the seaside of Virginia. Virginia Commission of Fisheries, Newport News

Losee, E. (1979). Relationship between larval and spat growth rates in the oyster (Crassostrea virginica). Aquaculture 16: $123-126$

Luckenbach, M. W. (1984). Settlement and early post-settlement survival in the recruitment of Mulinia lateralis (Bivalvia). Mar. Ecol. Prog. Ser. 17: 245-250

MacKenzie, C. L. Jr (1970). Causes of oyster spat mortality, conditions of oyster setting beds, and recommendations for oyster bed management. Proc. natn. Shellfish. Ass. 60: 59-67

MacKenzie, C. L. Jr (1981). Improving survival of seed oysters. In: Webster, D. (ed.) Oyster culture in Maryland, 1980. UM-SG-MAP-81-01. Maryland Sea Grant Press, College Park, p. 33-41

Mackin, J. G. (1946). A study of oyster strike on the seaside of Virginia. Cont. No. 25, Virginia Fisheries Laboratory, Newport News

Mackin, J. G. (1959). Mortalities of oysters. Proc. natn. Shellfish. Ass. 50: 21-40

McDougall, K. D. (1942). Sessile marine invertebrates of Beaufort, N.C. Ecol. Monogr. 13: 321-371

Michener, W. K., Kenny, P. D. (1991). Spatial and temporal patterns of Crassostrea virginica (Gmelin) recruitment: relation to scale and substratum. J. exp. mar. Biol. Ecol. 154: 97-121

Newell, R. C. (1979). Biology of intertidal animals. Elsevier, New York

Newkirk, G. F., Haley, L. E., Waugh, D. L., Doyle, R. (1977). Genetics of larvae and spat growth rate in the oyster Crassostrea virginica. Mar. Biol. 41: 49-52

Nichy, F. E., Menzel, R. W. (1967). Mortality of intertidal and subtidal oysters in Alligator Harbor, Florida. Proc. natn. Shellfish. Ass. 52: 33-41

Ortega, S. (1981). Environmental stress, competition, and dominance of Crassostrea virginica near Beaufort, N.C., USA. Mar. Biol. 62: 47-56

Paynter, K. T., DiMichele, L. (1990). Growth of tray-cultured oysters (Crassostrea virginica Gmelin) in Chesapeake Bay. Aquaculture 87: 289-297

Peterson, C. H., Black, R. (1987). Resource depletion by active suspension feeders on tidal flats: influence of local density and tidal elevation. Limnol. Oceanogr. 32: 143-166

Potter, M. A., Hill, B. J. (1982). Heat mortality in the Syndey rock oyster Saccostrea (Crassostrea) commercialis and the effectiveness of some control methods. Aquaculture 29: 101-106

Roegner, G. C. (1991). Temporal analysis of the relationship between settlers and early recruits of the oyster Crassostrea virginica (Gmelin). J, exp. mar. Biol. Ecol. 151: 57-69

Roegner, G. C., Mann, R. (1990). Settlement patterns of Crassostrea virginica (Gmelin, 1791) larvae in relation to tidal 
zonation. J. Shellfish Res. 9: 341-346

Roland, W. G., Albrecht, K. (1986). Growth and survival of Pacific oyster seed in Baynes Sound, B.C. - preliminary results. B.C. Maricult. Newslett. 6: 13-18

Roughgarden, J., Pennington, J. T., Stoner, D., Alexander, S., Miller, K. (1991). Collisions of upwelling fronts with the intertidal zone: the cause of recruitment pulses in barnacle populations of central California. Acta Oecol. 12: $35-51$

Spencer, B. E., Gough, C. J. (1978). The growth and survival of experimental batches of hatchery reared spat of Ostrea edulis L. and Crassostrea gigas Thunberg, using different methods of tray cultivation. Aquaculture 13: 293-312

Sumner, C. E. (1981). Growth of Pacific oysters, Crassostrea gigas Thunberg, cultivated in Tasmania. II. Subtidal culture. Aust. J. mar. Freshwat. Res. 32: 411-416

This article was presented by G. C. Harding (Senior Editorial Advisor), Dartmouth, Nova Scotia, Canada
Underwood, A. J., Fairweather, P. G. (1989). Supply-side ecology and benthic marine assemblages. Trends Ecol. Evol. 4: $16-20$

Utting, S. (1988). The growth and survival of hatchery-reared Ostrea edulis L. spat in relation to environmental conditions at the on-growing site. Aquaculture 69: 27-38

Walne, R. R. (1958). Growth of oysters (Ostrea edulis L.). J. mar. biol. Ass. U.K. 37: 591-602

Wisely, B., Holliday, J. E., Reid, B. L. (1979a). Experimental deepwater culture of the Sydney rock oyster (Crassostrea commercialis $=$ Crassostrea cucullata $)$. II. Pontoon tray cultivation. Aquaculture 16: 141-146

Wisely, B., Holliday, J. E., Reid, B. L. (1979b). Experimental deepwater culture of the Sydney rock oyster (Crassostrea commercialis $=$ Crassostrea cucullata). III. Raft culture of trayed oysters. Aquaculture 17: 25-32

Manuscript first received: March 31, 1994

Revised version accepted: September 14, 1994 